\title{
MateriatY
}

Klio. Czasopismo poświęcone dziejom Polski i powszechnym

PL ISSN 1643-8191, t. 28 (1)/2014, s. 153-183

(c) $($ ) $\ominus$

DOI: http://dx.doi.org/10.12775/KLIO.2014.007

Katarzyna PęKacka-FalKowska

(Poznań)

\section{Toruńska ordynacja przeciwdżumowa z 12 lipca 1710 roku}

W tem epidemii sprzed dwóch lat, rozpoczęła się w Toruniu w Zielone Świątki 8 czerwca $^{1}$. Świadczą o tym także liczne zapisy z zachowanych ksiag kościelnych: zarówno metrykalnych, jak i rachunkowych, które jednoznacznie wskazują na drugi tydzień czerwca jako początek kataklizmu. Przy czym stan podwyższonego zagrożenia epidemicznego utrzymywał się w mieście od pierwszych dni roku. Przykładowo, 13 stycznia w trakcie posiedzenia Rady Miejskiej informowano o narastającym zagrożeniu dżumowym w okolicy: zarówno na przedmieściach, jak i w jurydyce 2 . Coraz częstsze, acz wciąż nie masowe zgony dżumowe notowano w bliskim sąsiedztwie

${ }^{1}$ Por.: Archiwum Akt Dawnych Diecezji Toruńskiej (dalej cyt. jako AADDT), Parafia Św. Jakuba w Toruniu, AE 001, k. 95.

2 Archiwum Państwowe w Toruniu (dalej cyt. jako APT), Akta Miasta Torunia (dalej cyt. jako AmT), kat. II, II-14, k. 15 i nast. 
murów miejskich także w kwietniu i maju3 ${ }^{3}$ Jednak dopiero 3 czerwca w obliczu lawinowo rosnącej liczby zachorowań - zarządzono przygotowanie specjalnej proklamy skierowanej do zarażonych ${ }^{4}$. W obwieszczeniu podanym do publicznej wiadomości przez obwołanie go na ulicach miasta, przedmieść i Mokrego nakazano, aby wszystkie osoby, na których ciałach pojawiły się jakiekolwiek oznaki dżumy, oraz te, które mieszkały z zadżumionymi, nie opuszczały swoich izb aż do momentu całkowitego wyzdrowienia chorego, a to „pod czekającą ich nieomylną karą"5.

Mimo przedsiębranych w czerwcu przez Radę Miejską rozlicznych środków zaradczych - w mieście między innymi wprowadzono kontrolę ruchu ludności i towarów oraz obsadzono bramy nowymi strażami ${ }^{6}-$ za- $^{-}$ raza nieustannie przybierała na sile. Stąd też w kolejnym miesiącu, lipcu, III Ordynek zaapelował o wydalenie z miasta i przedmieść wszystkich zadżumionych oraz objęcie ich ścisłym nadzorem, aby „wskutek mieszania się zdrowych i chorych nie wybuchła zaraza dużo straszniejsza niż przed dwoma laty"'.

Przy czym dlatego, że dotychczasowe działania nie przyniosły oczekiwanych rezultatów, 11 lipca w trakcie kolejnego posiedzenia Rady zdecydowano się sięgnąć po nowe środki przeciwepidemiczne: nie tylko administracyjne, lecz i religijne. Senior toruńskiego ministerium, Ephraim Praetorius, przedstawił wówczas zalecane do rozważania w trakcie zarządzonego na 18 lipca dnia postu, pokuty i modlitwy teksty biblijne ${ }^{8}$. Ponadto wyznaczono wtedy czterech rajców w celu „przygotowania dobrego porządku i pokierowania chorobą"9. Wśród wybranych urzędników znaleźli

3 Zob. np. APT, AmT, kat. II, XVI-49, k. 917 i nast.; APT, AmT, kat. II, II-14, k. 65 .

${ }^{4}$ APT, AmT, kat. II, II-14, k. 83v.

5 Ibidem, k. 259 i nast.

${ }^{6}$ APT, AmT, kat. II, I-108a, k. 34; APT, kat. II, II-14, k. 91.

7 APT, AmT, kat. II, I-3800, k. 127 i nast.

${ }^{8}$ APT, AmT, kat. II, II-14, k. 97. Zob. przyp. 1 w edycji źródła. Więcej na temat porządku nabożeństw w Toruniu zob. np.: APT, EGW, św. Jerzy, t. 348, k. 5, 8v.

9 APT, AmT, kat. II, II-14, k. 95. 
się Jacob Giering ${ }^{10}$, Georg Austen ${ }^{11}$, Michael Willer ${ }^{12}$ i Andreas Schultz ${ }^{13}$. Następnego dnia oddelegowani do przygotowania zarządzenia przeciwdżumowego rajcy referowali tekst nowo napisanej ustawy. Za ich poruczeniem w kilka godzin później wydano także specjalne rozporządzenie, na mocy którego postanawiano ogłosić kwestę na rzecz miejskiej kasy morowej ${ }^{14}$. Natomiast kolejnego dnia zaczęto zaopatrywanie w żywność sześćdziesięciu chorych przebywających w budach w polu ${ }^{15}$.

Ustawa przeciwdżumowa z 12 lipca 1710 roku była najbardziej rozbudowaną spośród wszystkich zachowanych toruńskich porządków morowych z lat 1708-1710. Regulowała zarówno kwestie finansowe, jak i administracyjne czy sanitarne; zgodnie z jej zaleceniami zorganizowano miejskie służby przeciwepidemiczne.

Podstawę prezentowanej edycji stanowi kopia ordynku, która zachowała się w poszycie osiemnastowiecznych listów do Rady Miejskiej ${ }^{16}$. Przy edycji kierowano się zaleceniami niemieckiej instrukcji do wydawania tekstów wczesnonowożytnych z 1981 roku $^{17}$. Zgodnie z nimi zachowano oryginalną pisownię wyrazów, ortografię i interpunkcję. Zdublowane spółgłoski redukowano do pojedynczych. Nie rozwiązywano sygli.

${ }^{10}$ Funkcję rajcy nowomiejskiego pełnił w latach 1680-1711, w 1710 r. był sędzią nowomiejskim. J. Dygdała, Urzędnicy miejscy Torunia. Spisy. Część III: 1651-1793, Seria: Roczniki Towarzystwa Naukowego w Toruniu, R. 90, z. 2, Wyd. TNT, Toruń 2002, s. 66, 225; K. Pękacka-Falkowska, Genealogia toruńskiej rodziny Gieringów-szkic prozopograficzny, „Rocznik Toruński” 2007, t. 34, passim.

11 Urząd rajcy piastował w latach 1706-1716, w 1710 r. był panem wetowym. J. Dygdała, Urzędnicy, op. cit., s. 66, 219.

12 W latach 1706-1718 pełnił funkcję rajcy, w 1710 r. był scholarchą staromiejskim. Ibidem, s. 66, 246.

${ }^{13}$ Funkcję rajcy pełnił w latach 1706-1720, w 1710 r. był wójtem. Ibidem, s. 66, 241.

${ }^{14}$ APT, AmT, kat. II, II-8, k. 207; APT, AmT, kat. II, II-14, k. 97. Więcej na temat kolekt z 1710 r. oraz wysokości zebranych środków zob. np.: APT, AmT, kat. II, Akta luźne, 5102, k. 2 i nast.; APT, AmT, kat. II, Akta luźne, 5182, k. 8 i nast.

${ }^{15}$ APT, AmT, kat. II, Akta luźne, 5178, k. 12.

${ }^{16}$ APT, AmT, kat. II, I-3516, s. 119-161.

${ }^{17}$ Empfehlungen zur Edition frühneuzeitlicher Texte, „Archiv für Reformationsgeschichte" 1981, Bd. 72, s. 299-315. 


\section{Tekst źródłowy}

Źródto: APT, AmT, kat. II, I-3516: Briefe an den Rath, s. 119-161.

[k. 119]

Unvorgreifliches Bedencken E.E: Hochw. Raths den 7. Julÿ A. 1710. ausgesetzten $^{a}$ Deputirten, die Verordnung wegen jetzo grassierenden Gefährlichen Kranckheiten Betreffende, übergeben den 12 Julÿ. 1710.

Nachdem E.E.E. Hochw. Rath bereits die Anordnung gemacht, daß durch einen künftigen schon angesetzten ${ }^{\mathrm{b}-\mathrm{Bu}}$-, Beth-, und Fast-Tag ${ }^{-\mathrm{bl}}$ Gott dem Herrn in seiner Zorn=Ruthe gefallen, und derselbe, nechst Vergebung unserer aller Sünde, umb gnädige Abwendung der sich ziemlich eußern den ansteckenden Kranckheiten angerussen werden soll; Anbeÿ auch ein solcher Chirurgus ${ }^{c}$ bestellet ist ${ }^{2}$, der die durch solche Kranckheit befallene Persohnen in= und außer der Stadt fleißig besuchen und mit hiezu dienenden Artzneÿ=Mitteln treu, auch noch erheischander Nothdurft

a Wyraz nadpisany.

b--b Wyrazy podkreślone.

c Wyraz podkreślony.

17 lipca w trakcie posiedzenia Rady Miejskiej zarządzono, że „w celu odwrócenia niebezpiecznych chorób i ochrony przed nimi” 18 lipca zostanie ustanowiony dniem modlitwy, postu i pokuty. Stąd też 11 lipca senior toruńskiego ministerium, Ephraim Praetorius, przedstawił rajcom zalecane do rozważania w trakcie Buss-, Beth- und Fasttage teksty biblijne. O godzinie szóstej rano w toruńskich kościołach należało kazać na temat krótkiej perykopy z Ksiegi Psalmów, mianowicie wersów 14-16 z Psalmu 916. Na godzinę ósmą rano przewidziano rozważanie wersów 1-5 z trzydziestej ósmej części Księgi Mądrości Syracha, natomiast na południe - medytacje wokół wersów 14-15 z piątej części Listu św. Jakuba. Zob. np.: APT, AmT, kat. II, II-14, k., k. 95, 97; APT, AmT, kat. II, X-19, k. 296; J.H. Zernecke, Das verpestete Thorn, op. cit., s. 27.

${ }^{2}$ Najprawdopodobniej chodzi o Christiana Alexandra Pfauenkopfa. Zob. np.: APT, AmT, kat. II, I-3701, k. 705. 
mit Einhohlung eines guten Raths beÿ denen Herren Physicis ${ }^{3}$ hiesiger Stadt versehen möge: So erachten Wir nicht undienlich, sondern zu desto gewißerer Curirung derer Patienten gar nöthig zu seÿn, damit beÿ sich künftig |: davor Gott sey :| mehrd eußernden solchem ansteckenden Übel obrigem Chirurgo noch ein anderer zugegeben werde ${ }^{4}$, theils deßwegen, damit beÿ gehauften Patienten der Unzulängligkeit des einen, oder auch dem defect, wenn derselben einer mitangestecket und kranck [k. 120] werden möchte, zeitig vorgebeuget, theils auch weil der schon bestellte nur noch ein Gesell ${ }^{5}$, hirdurch den Patienten mit einem erfahrneren gedienet werden könte.

Und weil oben gedacht worden, daß der Chirurgus die Patienten erheischender Nothdurft nach, auch mit Einhohlung guten Raths beÿ denen Herren Physicis versorgen möge: mit dieser Einhohlung aber dem Patienten so nicht gedienet ist, alß wann ein erfahrner Medicus ${ }^{\mathrm{e}}$ selbst dieselbe persöhnlich besuchet, und von ihnen ihren Zustand eingentlicher Vernimmet, zugeschweigen der Gefahr, die denen Herren Physicis, und folglich, ihres freÿen Umbganges wegen, der Stadt durch solche obige öftere Communicirung mit deren Pest=Chirurgis obstehet; so wäre wohl dienlich !: ob solches zwar wegen jetziger Beschaffenheit der Stadt=Oeconomie mehr zu wünschen, alß zu hoffen stehet :! damit irgend ein erfahrner Medicus specialiter hiezu bestellet werden könte ${ }^{6}$.

d Wyraz podkreślony.

e Wyraz podkreślony.

${ }^{3} \mathrm{~W} 1710$ r. funkcję toruńskich fizyków miejskich pełnili Georg Peter Schultz i Nathanael Berend. J.H. Zernecke, Summarischer Entwurff des Geehrten und Gelehrten Thorns, Thorn 1712, s. 38.

${ }^{4}$ Rada postanowiła zatrudnić na tym stanowisku Friedricha Geymana, który przez cały czas trwania epidemii uchylał się od podjęcia obowiązków Pest-Chirurgusa. Zob. np.: APT, AmT, kat. II, II-14, k. 102.

5 Najprawdopodobniej chodzi o Joachima Wendego, urodzonego w Lauenburgu w Saksonii Lorentza Schultza lub Michaela Wagnera określanych w źródłach z tego okresu mianem Pest-Balbier Gessel. Zob. np.: APT, AmT, kat. II, II-14, k. 82, 94, 102; APT, AmT, kat. II, I-3444, k. 31.

${ }^{6}$ Jak się wydaje, w odróżnieniu od 1708 r., kiedy lekarzem dżumowym został Christian Balthasar Wiel, w 1710 r. żaden z lekarzy toruńskich nie objął tej funkcji. 
Wir denn auch Hochstnöthig nechst dem Leibe, auch vor die Seelen=Wohlfahrt Sorge zutragen, und diesem nach einen solchen ${ }^{\mathrm{f}}$ ordinirten Prediger ${ }^{-\mathrm{f7}}$ anzunehmen, der allen Patienten mit Trost, Unterricht und darreichung der Hochw. Sacramenten beÿspringen möge.

Diesen obgemeldten sämtlichen wird nun jedem besonders eine Wohnung ${ }^{g}$ anzuwiesen, auch ihnen ein solches Salarium ${ }^{\mathrm{h}}$ zu determiniren seÿn, dadurch sie zwar zu länglich versorget werden könten, in deßen mus hiebeÿ aller Überfluß und Unnöthigkeit der Außgaben Vermieden werden. Ihre Pflicht muß seÿn, [k. 121] nebenst dem communi officio besondere Treue und Feiß beÿ den Patienten anzuwenden, inzwischen nur schlechter dinges beÿ Ihnen sich brauchen zu laßen, des Umbgangesi aber mit andern Gesunden sich zu enthalten, wie imgleichen derer, so an andern gemeinen und nicht gefährlichen Kranckheiten liegen.

Weil aber alles obbeschriebene und grösten Theils auch das nachgesetzte ohne Unkosten ${ }^{j}$ nicht verrichtet werden kan, so ist haubtsächlich nöthig, die Gedancken auf die Aufrichtung einer zulänglichen und beständigen Cassa zurichten ${ }^{8}$; der Cämmereÿ solches anzumuthen, ist beÿ Ihren jetzigen schweren Außgaben weder möglich, noch billich eben ${ }^{\mathrm{k}} \mathrm{und}^{\mathrm{l}}$ was alle insgemein trifft dazu muß von allen ein Beÿtrag erfolgen. Unsere unmaßgebliche Gedancken wären diese:

1. Untersuche man die ${ }^{\mathrm{m}-}$ Vorraths $\mathrm{Gelder}^{-\mathrm{m}}$, und weil solche ohne dem ihre alte Widmung zu solchen außerordentlichen Fällen, welche inter Causas pias unstreitig maxime pia ist, haben, so nehme man den

f-f Wyrazy podkreślone.

g Wyraz podkreślony.

h Wyraz podkreślony.

${ }^{i}$ Wyraz podkreślony.

; Wyraz podkreślony.

k Wyraz skreślony.

${ }^{1}$ Wyraz nadpisany.

m-m Wyrazy podkreślone.

7 Tak jak dwa lata wcześniej, w 1710 r. w Toruniu nie powołano na urząd PestPredigera żadnego z lokalnych pastorów. Zob. np.: Książnica Miejska w Toruniu, Zbiory Specjalne, rkp. 130, k. 171-173v.

${ }^{8}$ W Toruniu miejski fundusz morowy (Pest=Cassa) działał ze zmienną intensywnością począwszy od 1708 r. Zob. np.: APT, AmT, Kat. II, 5178-5183, 5554-5555. 
Betrag davon hiezu, und trachte auch mit Hülffe der Ambter die Restanten mit Eifer einzutreiben.

2. Kann ein ${ }^{\mathrm{n}}$ Kirchen $=$ Stand $^{-\mathrm{n}}$ angeordnet werden, wozu künftigen Sontag der Anfang beÿ Abkündigung des Buß=Tages gemachet werden kan

3. Kan geordnet werden, daßein besonderer Klingbeutel ${ }^{\circ}$ in sämtl. auch in den Römisch=Catholischen Kirchen, item wegen des Kirchen Standes |: weil doch auf ihre Religions=Leuthe [k. 122] die meiste Außgaben gehen :! herumb gehe, nach deme Vorgängig der Endzweck deßen von der Cantzel der Gemeine kund gemachet werden wird.

4. Wird einen nicht geringen zu schub geben, wanno geordnet werden solte, daß in denen Quartieren durch besondere Bürger ${ }^{p-e i n e}$ Collecte gesammlet $^{-\mathrm{p}}$ werde: Solches kann geschehen entweder Monathlich auf einen bestimmten fest gesetzten Tag, oder aber, dafern das über Hand nehmende Übel einige Gefahr davon drauen solte, Ein vor allemahl, unbenannen, dafern in der Cassa ein Mangel verspühret werden sollte, daß solches repetiret werden könnte.

Wir zweifeln beÿ dieser gegenwärtigen gefährlichen Zeit an einer reichen beÿsteuer in allen obigen Vorschlägen nicht, und würde solcher zuschub desto zu länglicher seÿn, dafern die Cammerë̈ auß Ihrer bekanten Liberalite auch etwas dazu, es seÿ Ein vor allemahl, oder aber Monathlich oder Wochentlich, nach dero Gefallen, beÿtragen wollte, welches, weil es zu einer solchen Gottgefälligen allgemeinen Nothwendigkit angewendet wird, denenselben Gott der Herr desto reichlicher ersetzen wird.

q-Restriction des freÿen Umbganges. ${ }^{-q}$ Da auch nöthigist, damit in $=$ und außer der Stadt zwischen denen Bürgern und Einwohnern eine Anordnung gemachet werde; so wird insgemein ein und die andere freÿheit, welche sonsten beÿ gesunden und sichern Zeiten jedem unbenommen ist,

\footnotetext{
n-n Wyrazy podkreślone.

- Wyraz podkreślony.

p--p Wyrazy podkreślone.

q-- Wyrazy dopisane ma marginesie.
} 
auf gewiße Maß müßen restringiret und eingezogen, hergegen auch eines und das andere, so sonsten ungewöhnlich, eingeführet worden.

[k. 123] Vor allen Dingen ist das nöthigste, damit die Leuthe, so viel möglich, sich nicht durcheinander promiscue mengen, und wird also eine große Vorsicht gebrauchet werden müßen, in Einlaßung ${ }^{\mathrm{r}-}$ frembder Persohnen ${ }^{-r}$ und Sachen: zu wünschen wäre es wohl, daß Wir in dem Stande wären, und durch eine Landes=Verordnung einiger maßen wegen, die ins Land auß frembden Örthern kommenden subleviret würden; Allein, da Ursachen bekandt, warumb es nicht seÿn kan, so ist dieserhalb eine desto größere Vorsorge von Seiten hiesiger Stadt zumachen. Wir erachten unvorgreiflich in diesem nöthigen Puncto das dienlichste zu seÿn.

1. die vor denen dreÿ Haubt-Thören, alß Brücken; Culmischen und St. Jacobs-Thor aufgerichteten Buden, nebst denen hiezu bestellten Aufseherns beÿzubehalten, derer Pflicht seÿ, auf die einkommende Persohnen und Sahnen genau Acht zu haben, kein Geschencke und Gaben zunehmen, oder auß Gunst je $e^{t-m a n}{ }^{-t} d e n$ jeden ohne Anmeldung und Verwilligung der Praesidence in die Stadt zulaßen, und sich stets und fleißig an dem Ihnen angewiesenen Thor zubefinden. $\mathrm{Ob}$ er nur deßen nur bloß auf seinen bürgerlichen Eÿd zuerinnern, oder aber hierauf Specialiter in den Eÿd ${ }^{u}$ zunehmen seÿn wird, sollen wir E.E.Hw. Rath anheim.

[k. 124] 2. Niemanden frembden von Persohnen und Sachen hereinzulassen, Er habe dann ein glaubwürdiges Attestatumw', welches Atesstatum aber der Aufseher vorgängig an das E. Praesiderende Amt zusenden befugt seÿn wird.

3. Eingleiches soll auch gehalten werden von Bürgern und ihren Sachen, wenn sie auß frembdern Örthern zurück kommen.

4. Außer denen obigen 3. Haubt=Thoren, ohne große Nothwendigkeit, keine öffnen zulaßen, und wenn ${ }^{\mathrm{x}}$ es ja eines

r-r Wyrazy podkreślone.

s Wyraz podkreślony.

t-t Wyraz nadpisany.

"Wyraz podkreślony.

w Wyraz podkreślony.

× Wyraz podkreślony. 
oder des andern Bürgers Nahrung halber geöffnet würde, der Schildwache ernstlich mitzugeben, außer dem, was zu Verrichtung solcher des Bürgers Nahrung dienet, Niemanden ${ }^{y}$ einzulaßen, sondern allesammt an eines von denen obgedachten 3. Haubt Thören zuweisen, daselbst Er seine weitere Weisung erhalten soll.

5. So wohl dem Aufseher beÿ denen 3. HaubtThören, alß auch denen Schildwachen anzubefehlen, hiemit sie die frembden nicht gar ${ }^{\mathrm{z}-\mathrm{zu}} \mathrm{Nahe}^{-\mathrm{z}}$ an sich kommen laßen mögen, auch sich enthalten ihre Sachen zu berühren.

6. Die Posten ${ }^{\text {aa }}$ betreffende.

[k. 125] 7. Was die Einlaßung obrige Posten ${ }^{\mathrm{ab}}$ Persohnen $^{\mathrm{ac}}$ und Sachen in die Vorstädte ${ }^{\text {ad }}$ betrifft, so könte woll einige Anordnung hierinn vorgeschlagen werden; allein da bekand ist, in welchem Zustande dieselbe seÿe, und man sie auch wegen gar wenig darinnen befindlichen Einwohner, insonderheit wegen gar irregulairen An= und Bebauung nirgends schließen kan, so wird die meiste Vorsicht in diesem Stück auf die Stadt gewendet werden müßen; indeßen aber wird ohne frucht nicht ${ }^{\text {ae }}$ seÿn, wann denen RottMeistern in jedem Vorstädtischen Qvartier und auf der Mater ${ }^{\text {af }}$ dem Schultzen anbefohlen wird, damit die Schultzen zwar durch ihre umbzech hiezu außgesetzte, beÿ Ihren Schlagbäumen, die ersten aber auf denen offentlichen Land=Straßen alle Persohnen und Sachen so gar ohne Pässe ${ }^{\mathrm{ag}}$ komen, zurückweisen, die aber welche haben an die StadtThöre zu ihrer weiterer Weisung laßen mögen.

6. Die Jenigen nun, die einen glaubwürdien $\mathrm{Pa}^{\text {ah }}$, so wohl auf Persohnen, alß Sachen, jedoch alle genau specificiret, und zugleich eine darauf befindliche authentische [k. 126] Aufzeichnung derer

y Wyraz podkreślony.

z--z Wyrazy podkreślone.

a Wyraz podkré́lony.

ab Wyraz skreślony.

ac Wyraz nadpisany.

ad Wyrazpodkreślony.

ae Wyraz nadpisany.

ag Wyraz podkreślony.

ah Wyrazpodkreślony. 
unverdächtigen Örther, dadurch sie gereiset, haben, können als unverdächtige eingelasßen werden: die Jenigen aber, so gar keine ${ }^{\text {ai }}$ haben, werden billich gar abgewiesen. Welche aber einem haben, auß einem solchen Orth, von deßen Inficirung man nur muthmaßet, werden ihre Qvarantaine von 40. Tagen an denen ehemahlen angewiesenen Stellen außzustehen haben ${ }^{9}$.

So wird auch nöthig seÿn die Uberfuhr gar einzustellen und die Brahmen zu Versencken, nicht minder durch eine schon ehemehls geschehene Anordnung zuverhütten, daß die Communication von jener Seite der Weichsel durch Privat Lodzien nicht fortgesetzet werden.

$\mathrm{Zu}$ diesem Endzweck wird auch gehören, damit die hiesigen Bürger und Einwohner sich aller öffentlichen und haüffigen ZusammenKünfte ${ }^{\text {aj }}$ möglichst enthalten, alß da sind

1. HochZeiten ${ }^{\mathrm{ak}}$,

Diese weil sie völlig nicht zuheben sind, könten einige Zogen werden irgend beÿ den Handwerckern auf 28 Persohnen, und beÿ den Vornehmern biß 36. Persohnen. Was darüber; kan mit gewießer Strafe von jeder Persohn zu einen specie thlr der Pest Cassa zum besten [k. 127] beleget werden: ferner sie können eingezogen werden auf eine gewiße Zeit, den Handwerckern etwa biß 9. Uhr und den Vornehmen biß 11. Uhr Abends: die Täntze könten woll gar eingestellet werden: doch, weil der Kunst-Pfeifer hierunter Schaden leidet, und es ein pars Salarii ipsius mit ist, so wird ihme müßen worinnen dieses einiger maßen bonificiret werden; irgend, daß die Braut=Leuthe demselben eine gewiße Erkäntligkeit reichen mögen, welche aber umb alle künftige Weitläufigkeiten zuvermeiden, von E.E.Hw. Rath determiniret werden muß cum distinc-

ai Wyraz podkreślony.

aj Wyraz podkreślony.

ak Wyraz podkreślony.

${ }^{9}$ Kwarantanny odbywały się m.in. w nowo budowanych szopach na kępie wiślanej naprzeciw Smolnika oraz na polach otaczających miasto od strony północno-zachodniej. Zob. np.: APT, AmT, kat. II, I-3798, k. 228-235; APT, AmT, kat. II, II-13, k. 73-76; APT, AmT, kat. II, II-14, k. 89. 
tione, was Handwercker und Vornehmere geben sollen: Sonsten werden sie sich auch dabeÿ allen Überflußes in Auftragung der Gerichte, wie auch aller beÿ jetziger Zeit gefährlicher Uberladung in Eßen und Trincken enthalten, darauf der E. Wette Acht zuhaben commitiret werden kann.

2. GastGebotheal,

Diese, weil es freuden Mahle und gegenwärtige Zeiten TrauerZeiten sind, konten woll gar [k. 128] eingestellet werden, worunter der Handwercks Leuthe, vornehmlich aber ihrer Gesellen gewöhnliche Zechen, auf denen herbergen, frembder Gesellen Schenckungen und anderer weitigen zusammen Künfte gehören, doch unbenommen, wenn gute freunde einander auf Haußmanns Kost zu sich laden, oder sonst zusammen kommen.

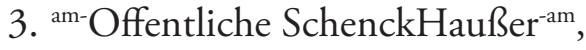

Solte sie Plage, |: davor Gott seÿ :| recht einweißen, so wären vor allen Dingen sofort die offentl. Bürger Schie ${ }^{\text {an }}$ und Juncker-Garten zu schließen: unter deßen ist beÿ jetzigen Zeiten doch nöthig zu verhütten, damit nicht verdächtiger miteingelaßen, und die andern auch nicht häufig untereinander sitzen und Gemeinschaft haben mögen.

4. Offentl. BadStuben ${ }^{\text {ao }}$,

Diese, weil sie unstreitig zu diesen Zeiten gefährlich, müßen gäntzlich eingestellet werden, wie wohl gar nöthig ist, daß deßwegen dem Bader, alß welcher der Cammereÿ die gewöhnlich Zinse zahlen muß, einige Bonificirung geschehe.

5. [k. 129] Offentl. LeichenBegängnüße ${ }^{a p}$.

Weil unstreitig, daß wo ja beÿ einer zusammen Kunft, so gewiß beÿ einer Leichen Begängnüß große Vorsicht gebrauchet werden müß,

al Wyrazpodkreślony.

am--am Wyraz podkreślony.

an Wyraz skreślony.

ao Wyraz podkré́lony.

ap Wyraz podkreślony. 
absonderlich eines in gegenwärtigen grassirenden Kranckheiten verstorbenen, so wäre wohl dienlich, damit solche Begängnüße, weil sie doch nicht völlig eingestellet werden können, mit der unter sub Titulo Verstorbene $\$ 3$. et 5 . breiter vorgeschlagene Vorsicht verrichtet werden möge.

6. ${ }^{\text {ar-Kirchen und Schulen }}{ }^{-a r}$,

Hierin Vermeinen Wir unmaßgeblich, dafern Gott der Herr mit der Plage ernster wieder uns Verfahren würde, daß die letzteren völlig geschloßen, in der erstern aber die Anordnung gemacht werden möchte, hiermit die Verdächtige sich derselben; so wie aller andern Gesellschaften, völlig enthalten, die andern aber, so viel alß möglich, nicht zu enge und häufig beÿ sammen sitzen mögen: Unter deßen würde nicht undienlich seÿn, damit beÿ gegenwärtigen Kranckheiten wegen Zärtligkeit der Jugend, [k. 130] die solchen Übel am meisten unterwürfig ist, und da ohn den die gegenwärtige Zeit der HundsTage zu solchen Schul vacationibq Gelegenheit giebet, durch den Hn. Rectorem Gymnasii der sämtl. Jugend auf einige Wochen Ferien geben werden mögen, worinnen auch schon durch Se.E.Herrl. Verordnung geschehen ist; die ersteren müßen fleißig gereichert werden.

$2^{\text {as at }} \mathrm{E} \beta=$ und Trinck $=$ Sachen ${ }^{\text {at }}$.

Weil auch gewiß, daß beÿ solchen Zeiten in denen Speiß= und TrinckSachen eine Distinction gemachet werden muß, indem von solchen, wenn es ungesunde Sachen sind, das Ubel nur vermehret und größer gemachet wird; so wärden Unser unmaßgebliche Rath ${ }^{\text {au }}$ Vor ${ }^{\text {aw }}$ schläge.

1. Hiemit alle dergleichen Sachen, so schädlich sind, in die Stadt ein zuführen und zu verkaufen gäntzlich verbothen, hergegen die, so dem Übel wiederstehen können, so viel möglich, angeschafet

\footnotetext{
ar--ar Wyrazy podkreślone.

as Cyfra skreślona.

at--at Wyrazy podkreślone.

au Wyraz skreślone.

aw Prefiks nadpisany.
} 
werden mögen, worüber derer Hhn. Physicorum Gutachten einzuhohlen seÿn wird.

2. [k. 131] Können ax-ā parte MarckPlätze ${ }^{-s x}$ angewiesen werden, alß vorm Culmschen Thor nach dem AltThornischen $\mathrm{Zu}$ und vorm den Jacobs'Thor in den großrn Rundel, imgleichen an der Weichsel die SaltzWaren, doch mit dieser Behutsahmkeit, daß sie etwas ${ }^{\text {ay-weit von }}{ }^{\text {-ay }}$ einander feil halten möchten, und ein jeder Eßig oder Waßer in einen Gefäß habe, das Geld ${ }^{\mathrm{az}}$ darinn zu legen. $8^{\text {ba }}$ Rein ${ }^{\text {bb-haltung der Gaßen }}{ }^{\text {-bb }}$,

In diesem höchstnöthigen Punckte, woran ein großes gelegen, wäre Unsere unvorgreiffliche Meinung dieser

1. Alle Unlust von den Gaßen und hinter den Mauern außzuführen, den frisch hingeworfenen zwar, daß ihn die Bürger außführen $6^{\text {bc }}$ vor $1^{\text {bd }}$ und $2^{\text {be }}$ hinter $3^{\text {bf }}$ den $4^{\text {bg }}$ Häusern $5^{\text {bh }}$ : den alten ${ }^{\text {bi }}$ etwan hac methodo: daß entweder die Kämmereÿ oder der $\mathrm{Hl}$. QuartierAmbts Prasident, wozu er sich ehemahl willig erbothen, über sich nehmen, Pferde und Wagen anzuschaffen, und was es Kostet, kan von den Häusern und derselben [k. 132] Einwohnern nach Proportion der Häuser wiedergenommen werden. Und wenn von einem oder dem andern Orthe hinter Mauren die Unlust außgeführet worden, diesen Platz mit Gegittern zuverschlagen.

2. $\mathrm{Zu}$ verbiethen, damit nichts auf die Gaßen geworfen, gegoßen, oder geschüttet werde, welches einen Gestanck ${ }^{\text {bj }}$ oder den Augen

\footnotetext{
ax--ax Wyrazy podkreślone.

ay--ay Wyrazy podkreślone.

az Wyraz podkreślony.

ba Cyfra skreślona.

bb--bb Wyrazy podkreślone.

bc Cyfra nadpisana.

bd Cyfra nadpisana.

be Cyfra nadpisana.

bf Cyfra nadpisana.

bo Cyfra nadpisana.

bh Cyfra nadpisana.

bi Wyraz podkreślony.

bj Wyraz podkreślony.
} 
ein Grauen und Entsetzung verursachet, zu welchem Ende auch das Saltz, Stockfisch, dorsch, und ander dergleichen Waßer nicht auf die Gaßen gegoßen, sondern entweder auf ${ }^{\mathrm{bk}}$ in die Bache oder in die Weichsel getragen werden soll.

3. Und weil auch so wohl die Stadt ${ }^{\text {bl-hinter den Mauren }}{ }^{-b l}$ zwischen den WaßerThoren an den StadtMauren und hin und wieder große Unreinigkeit und Gestanck wegen der salva venia daselbst befindlichen Unreinigkeit verspühret werde, wodurch die Luft infisiret wird; alß ist eine von der grösten bißhero lang desiderieten Nothwendigkeit, gewieße publique Abtritte ${ }^{\mathrm{bm}} \mathrm{zu}$ verfertigen. Unvorgreifflich könten dazu Örther angewiesen werden $\mathrm{Ort}^{\mathrm{bn}}$ an der Weichsel, etwa

1. unter der Brücken,

2. beÿ der Winde,

3. an der Müntze,

4. auf der Fischereÿ

Solche könten auch angeleget werden auf der bo-Bache, allem weil sie wegen Verhinderung der Edelleuthe nicht Jährlich gereiniget werden kann $^{\text {bo }}$ nach dem Exempel anderer Örther, auch außtrucknet, so müste man es dabeÿ laßen; Unmasgeblich wären die beqwemsten Orther dazu beÿ dem HirschWinckel ${ }^{\text {bp }}$, wo es ehmahls gewesen, 2) beÿ den ${ }^{\text {br-Thor nach }}$ der Neustadt ${ }^{-b r}$ gegen, dem Schießgraben, da es auch ehmahls gewesen.

$\mathrm{Zu}$ diesem Behufs wird nun auch nöthig së̈n, damit alle Häuser, sonderlich $^{\text {bs-die jenigen }}{ }^{\text {-bs }}$, so dergleichen nicht haben, ihre Privat-Abtritte, laut alter E.E: Rath Verordnung, haben mögen, keines weges aber ihre Unlust, außerhalb Ihren Häusern, es seÿe dann auf denen dazu aufgerich-

\footnotetext{
bk Wyraz skreślony.

b- -bl Wyrazy podkreślone.

bm Wyraz podkreślony.

bn Wyraz skreślony.

bo--bo Wyrazy podkreślone.

bp Wyrazpodkreślony.

br--br Wyrazy podkreślone.

bs--bs Wyrazy podkréslone.
} 
teten Privat-Abtritten, werden selbst nach ihre Kinder [k. 134] Gesinde und Haußgenoßen entladen, vielweniger auß schütten mögen.

Hunde werden nöthig seÿn, daß der ScharfRichter sie wegschaffe, des Tages zwar mit Fangen, des Nachts aber mit Schlagen, wie imgleichen, daß die Hüner, Enten und dergleichen ander Vieh von den Gaßen geschaffet werden, wiedrigen falls sie von den Thurm Knechten weggenommen werden könten.

Und da bereits in der Willkühr verordnet worden, daß keiner befugt seÿn solle, in der Stadt sal. v. Schweine ${ }^{\text {bt }}$, Kühe oder ander dergleichen Viehe zuhalten, so wäre nöthig, damit die Hln. QvartierHerren, insonderheit beÿ diesen Zeiten, durch die RottMeister darauf Acht haben mögen, und falls etwas dergleichen betroffen würde, solches so fort alles, nach vorgängige Verwahrnung und Ansetzung einer Zeit von 24 Stunden, zu confisciren, auch ein jeden besonders zubestrafen.

$\mathrm{Zu}$ dieser Reinhaltung der Gaßen und Straßen wird auch gehören, daß die hin und wieder auf den Gaßen, auch auf den Vorstädten, sonderlich aber nahe an den Stadt Thoren und LandStraßen befindliche, Theils gehende, theils liegende, ja zum theil auch todte arme Persohnen, bettlere etc. [k. 135] abgeschaffet werden mogen.

Bettlere. $^{\text {bu }}$ Und da bereits vom E.E.Rath hier auf ${ }^{\text {bw }}$ über $A^{\circ} 1708 \mathrm{~d}$ 5. Sept. ${ }^{10}$ eine Verordnung geschehen, so erachten wir, daß es auch dabeÿ sein bewenden haben kan, nemlich, daß auß solchen an einen Ort vor der Stadt zusammengetriebenen sämtl. Bettlern beÿderleÿ Geschlechts, die gesunden $^{\text {bx }}$ mit zuziehung der Chirurgorum, auch, wo es seÿ kan, der Hln. Physicorum außgesuchet, und zu unten benanten Bedienungen, wehrender Pest=Zeit, nach Beschaffenheit und zulänglichkeit der Persohnen, gegenst gewißen Lohn auf jede Woche[?], genommen, die ${ }^{\text {by }}$ aber solches nicht eingehen wollten, sofort, alß schädliche und arbeitschauende Müßiggänger, gantz und gar, ohne die geringste Zehrung weggejager werden mögen,

\footnotetext{
bt Wyraz podkréślony.

bu Dopisek na marginesie.

bw Wyraz skreślony.

bx Wyraz podkreślony.

by Wyraz podkreślony.

10 Zarządzenie nie zachowało się do naszych czasów.
} 
mit Bedrohung, falls sie sich wiederfinden laßen sollten, man sie so gleich alß Pestverdächtige unter die würcklich verpestete ins Pest-Hauß bringen würde.

Mit den jenigen aber so zwar von den Infection annoch frë̈ erfunden werden, hingegen aber sonsten Unvermögend ${ }^{\mathrm{bz}}$, und an händen, füßen und [k. 136] dergleichen andern Leibes Zufällen gebrechlich, oder auch Alters wegen, gar schwach sind, kan kein ander modus vor die Hand genommen werden, alß daß sie entweder beÿ der Stadt in irgeinem gewißen anzuwiesenden Orte und Hause |: weil die ordentliche Spitähle hiezu nicht gebrauchet werden können :| ca-ex publico-ca täglich versorget, und ihnen hiedurch alle Nothwendigkeit benommen würde, ihr Brodt durch hierum vagiren und Antretungen um die Leuthe zu suchen oder aber, daß man ihnen, Laut E.E.Hw.R. oben allegirter Verordnung von Ao 1708. zu 10 biß 30 g. jedem reiche und gäntzlich ${ }^{\mathrm{cb}}$ von der Stadt und Vorstädten schaffe. Weil wir aber das letztere vor etwas hart und so geartet ansehen, daß es mit der Christlichen Liebe einiger maßen zustreiten scheinet, in deme viele unter ihren solche Persohnen seÿn können, die Alters und andern habenden Zufalls halber, entweder gar nicht, oder doch gar kümmerlich fortwandern können: So erachten Wir den erstern modum, ob er wohl dem publico beschwerlicher seÿn wird, dennoch angesicheter Christlicher Liebe gemäßer zuseÿn, es seÿn dann, daß, weil dergleichen Leuthe der Infection ihrer armseeligen Lebens-Ort [k. 137] wegen leichter unterwürfig, und also folglich, wenn sie nahe beÿ der Stadt verpfleget werden solten, vor dieselbe Stadt gefährlicher sind, daß man sie diesem nach etwas weiter von den Stadt, etwan auch auf eine von den WeichselKempen schaffe, und ihre tägliche Verpflegung zukommen laße.

Mit denen aber so würcklich ${ }^{\text {cd }}$ Kranck sind, wird es eine andere Einrichtung bedürfen. Wir vermeinen ohnmaßgeblich, daß sie alle ins PestHauß, und zwar, wir es mit andern geschiehet, die würckliche und gewiß inficirte in ein besonders, die Verdächtige aber auch in ein besonde-

\footnotetext{
bz Wyraz podkreślony.

ca--ca Wyrazy podkreślone.

cb Wyraz podkreślony.

cd Wyrazpodkreślony.
} 
res Zimmer, oder aber, wofern darinnen bereits wenig Raum wäre, außerhalb demselben ins feld unter Stroh-Hütten, doch jede Sorte besonders, gebracht und geschaffet werden mögen.

So erachten Wir beÿ dieser Gelegenheit auch nicht undienlich zuseÿn, wenn denen armen auß hiesiger Stadt samtl. Spitählen ${ }^{\text {ce }}$ der Umbgand völlig vorjetzto untersorget ${ }^{\mathrm{cf}}$ werde, in deme dergleichen Umbgehende den Unterscheid der Hauser so eigentl. nicht machen [k. 138] können, und ihrentwegen auch ein Jeder selbst besorget seÿn wird.

cg-Verpestetes Hauß und Persohnen ${ }^{-\mathrm{cg}}$.

Weil unstreitig ist, daß dem ansteckenden Übel am sichersten, nechst Göttl. Hülfe, gesteuret wird, wenn man auf Häuser, Persohnen und Sachen, welche solches Unglück betroffen, gute Vorsicht brauchet, so scheinet es wohl das sicherste zuseÿn, wann solche Häuser, so bald sich ein inficirter ${ }^{\text {ch }}$ Krancker darinnen findet, oder ein Todter ${ }^{\mathrm{ci}}$ herausgeragen wird, so fort mit der gantzen Familien zugeschlagen werde. Wir erachten aber ohnmaßgeblich gleich sicher zu seÿn, und der Christlichen Liebe näher zu kommen:

$1 .{ }^{11} \mathrm{da}$ sobald sich dergleichen in einem Hause mercken laßen solte, allen in dem Hause befindlichen angedeutet werden solle, hiemit sich ein Jeder auf eine gewieße Zeit, irgend von ${ }^{\mathrm{cj}} 6$. Wochen ${ }^{-\mathrm{cj}}$, des Ausganges ${ }^{\mathrm{ck}}$ beÿ Strafe enthalten möge, darauf die unten benandten Pest=Aufseher, jeder in seinem angewiesenen Qvartier, Acht haben, und wer darwieder handeln würde, [k. 139] denselben der Prasidence sogleich anmelden wird, beÿ untengesetzter Strafe. Solchen Persohnen aber soll ihre Nothdürft ${ }^{\mathrm{cl}}$ durch die in je-

ce Wyrazpodkreślony.

cf Wyraz podkreślony.

cg- -cg Wyrazy podkreślone.

ch Wyraz podkreślony.

ci Wyraz podkreślony.

cj-cj Wyrazy podkreślone.

ck Wyraz podkreślony.

cl Wyraz podkreślony.

${ }^{11}$ Punkty od 1 do 4 powtórzono w Magistratus Conclusum die 29. Aug. Anno 1710. Zob.: APT, AmT, kat. II, XIII-21, k. 155-159. 
dem Quartier bestellte Pest-Zuträgere gegenst Zahlung, wenn sie Vermögend sind, oder wenn sie nicht beÿ paraten Mitteln, $2^{\mathrm{cm}}$ auf Caution, die ein guter freund solchen Hauses, gegenst Versicherte WiederErstattung, auß Christl. Liebe, und weil es ohne seinen Schaden geschiehet, zweifels ohne willig auf sich nehmen wird, oder aber, wenn sie gantz nothorische arm $3^{\mathrm{cn}}$, ex publico gereichet werden.

2. Sollte aber ein oder mehr Gesunde Schau tragen ${ }^{\text {co }}$ in dem selben Hause zu bleiben; so könte ihnen der Außgang ${ }^{c p}$ gar wohl gestattet werden, doch zu der gestalt, entweder daß sie Sich durch ein gewißes Zeichen ${ }^{\text {cr }}$ von den anderen unverdächtigen unterscheiden, etwan mit einem weißen Stabe in der Hand, oder mit einem rothen, weißen, oder ander färbichehten, Kenntlichen Zeichen auf dem Hutte, Mütze, Kragen [k. 140] oder Rocke, welches umb gewißerer Käntniß willig auf ein gewißes determiniret werden muß; inzwischen sich allen nahen ${ }^{c s}$ Antrittes an die Leuthe, wie imgleich aller solcher Orther, da viele Leuthe zusammenKünfte sind, worunter die Kirchen mit begriffen, gäntzlich beÿ Strafe des gantzen Verschlußens, oder auch Verschlagens des Hauses enthalten. Oder aber könte ihren der Außgang verstattet werden, daß ${ }^{\text {ct }}$ zu der gestalt, daß sie sich so gleich auß der Stadt und Vorstädten machten, und entweder gar Wegzögen, oder irgend im Felde ${ }^{\mathrm{cu}}$ entfernet von der Land Straßen, sich aufhielten, keines weges aber sich in hiesiger Stadt LandGüter wer der auch seÿn, verfügen mächten, beÿ obiggedachter Strafe.

\footnotetext{
cm Cyfra nadpisana.

cn Cyfra nadpisana.

co Wyraz podkreślony.

сp Wyraz podkreślony.

cr Wyraz podkreślony.

cs Wyraz podkreślony.

ct Wyraz skreślony.

cu Wyrazpodkreślony.
} 
3. denen Würcklichen Krancken bleibt aller Außgang Verbothen, wie auch denen, so in ${ }^{\mathrm{cw}-}$ etwas schon gemesen ${ }^{\mathrm{cw}}$ sind, sondern es werden die Letztern darinnen eine Zeitlang Verbleiben, welches, wie lang es seÿn soll, zu determiniren, wegen Ungleichheit der Kranckheit und Patienten. Wir schwer $\mathrm{p}^{\mathrm{cx}}$ zu seÿn [k. 141] erachten, sondern es denen HHn. Medicis und Chirurgis überlaßen, solcher gestalt, daß es beÿ Ihrem Judicio stehen kan, wie lange dieser oder anderer gemesende Patient schon sicher wird außgehen können. Es seÿe dann, daß solchen Patienten zu seiner völligen Aufkommung, die ${ }^{\text {cy-frische Lufft }}{ }^{-c y}$ und Veränderung der selben Höchstnöthig und nützlich wäre, alß dann könte man Ihnen den Außgang außerhalb der Stadt ins öffene Feld woll gönnen, doch ${ }^{c z}$ damit, mehrer Sicherheit wegen, sie entweder schon daselbst biß zu ihrer Völligen Genesung bleiben, oder nicht anders, dann mit dieses Qvartiers bestellten Pest=Aufseher wieder in die Stadt, und folglich ins vorige Hauß kommen mögen.

4. Weil auch beÿ jetziger Zeit an manchen HaußWirthen und HaußWirthinen dieses gar unChristl. Verfahren abgemercket worden, daß, wann auß ihrem Gesinde ${ }^{\text {da }}$ Jemand Kranck geworden, sie solches, aller Liebe und billigkeit zuwieder, sofort $1^{\mathrm{db}}$ auß dem Hause gejaget, oftmahlen gar ohne [k. 142] mitgegebene Zehrung, nicht minder, daß sie $2^{\text {dc }}$ Todte Persohnen auß ihren Häusern auf die Gaßen beÿ NachtZeiten außlegen, ja gar umb ihr Hauß nicht im Verspruch zubringen, solche $3^{\text {dd }}$ in ihren gedachten Häusern, Höfen und Stallungen begraben. Daher es denn geschehe, daß sowohl in der Stadt an den Mauern, alß insonderheit in denen Vorstädten hin= und wieder zum Abscheu

cw--cw Wyrazy podkreślone.

cx Litera skreślona.

cy-cy Wyrazy podkreślone.

cz Wyraz podreślony.

da Wyraz podkreślony.

db Cyfra nadpisana.

dc Cyfra nadpisana.

dd Cyfra nadpisana. 
der Vorbeyggehenden, unterschiedliche Krancke liegend, ja oftmahlen Zappelnd, und auch todte Leichen gefunden worden, denen sonsten geholfen werden können, wenn sie barmhertzigere und Christlicher Brodherren oder Brodtfrauen gehabt hätten. So wäre wohl nöthig, damit solches alles durch ein angeschlagenes Edictum $^{\text {de }}$ beÿ Nahmhafter Strafe ernstlich Verbothen, und solchen HaußVätern und HaußMüttern angedeutet werden, hiemit sie solches Kranckgewordene Gesinde und andere Persohnen dem deßfalls täglich etlichmahl herumbgehenden Pest=Aufseher mel$\mathrm{den}^{\mathrm{df}}$ mögen. Ubrigens über dergleichen kranck oder todt liegende [k. 143] Persohnen genaue Acht zuhaben den Pestaufsehern, jedem in seinem Qvartier, mit Nachdruck anbefehlen werde, mit denen und Erstern er seiner unten beschriebener Pflicht gemäß, ohne Säumniß zu Verfahren schuldig seÿn wird.

5. Beÿ zunehmendendg Übel wird unvorgreifflich eine größere Vorsicht wegen solcher inficirten Häuser zu brauchen seÿn, und weil Wir oben erachteten, daß die Zuschlagung derselben etwas zu hart ist, gesunden nehmlich mit den Krancken in einem oftmahlen unbeqwemen Hause zusammen einzusperren, da dergleichen Gesunde von der bloßen Furcht, Einbildung, Bangigkeit, steten Umbgang, der kaum zu Vermeiden seÿn würde, mit den Krancken und andern daher rührenden Gelegenheiten, leicht, ja nothwendig mit Kranck werden und sterben müste. So wäre dieses Unserer Meinung nach zulänglich genung [?], den durch solche Verschlagung abgeziehlten Endzweck zuerreichen, daß man nemlich solch inficirtes Hauß mit einem gewißen [k. 144] Zeichen $^{\text {dh }}$, etwan einem rothen, schwartzen oder weißen Kreutz, oder auch mit einem außgehangenen weißen Gewand, oder zum fenster außgesteckten Kleinem Stroch=Gebünde, oder sonsten anders bemercke, welches damit es allen Kundt werde, durch ein an-

\footnotetext{
de Wyraz podkreślony.

Wyraz podkreślony.

Wyraz podkreślony.

dh Wyraz podkreślony.
} 
geschlagens Edictum notificiret werden könte, darinnen zugleich die Warnung annectiret werden kan, damit

6. sich Niemand wage in dergleichen gezeichnetes Hauß zugehen, wird eigen falls derselbe so fort auß der Stadt geschaffet werden solle, umb daselbst an einem entferneten und abgelegenen angewiesenen Orthe eine Zeit von 14 Tagen außzuhalten, oder aber: daß Er schuldig seÿn wird, sich diese gedachte Zeit über in seinem Hause einzuhalten, oder wenn er außergehen wolte, hiezu nicht anders berechtiget seÿn solle, alß mit oben beschriebenem Zeichen, alß Puncto 2. erwehnet, von andern unverdächtigen Leuthen unterschieden.

7. Weil auch die Erfahrung lehret, wie viele, welche würcklich von dem grassierenden Übel ergrieffen worden, und deßen Zeichen Bereits am Liebe eußerlich tragen, dennoch [k. 145] deßen ungeachtet, wieder die Leibe des Nächsten, wißentlich ${ }^{\text {di }}$ unter Leuthe sich mengen, und hiedurch gesunde anstecken, folglich die Seuche immer mehr und mehr außbreitend machen. So wäre Unser unmaßgebliche Meinung, damit solchem sehr gefährlichen malo durch ein Edictum ${ }^{\mathrm{dj}}$ zeitig und ernstlich vorgebeuget, und diesemnach solches mit Nachdruck untersaget werde; zugleich auch verordnet, daß, welcher darinnen wißentlich betroffen würde, solcher mit nachdrücklicher Bestrafung, auch, wie es ein solcher wohl verdienet, mit einer Leibes=Strafe angesehen werde, darüber alle untengenante PestBediente, insonderheit die Pest=Aufseher genaue Acht haben werden.

8. Sollte nun ein solches Hauß entweder durch Außtragung der Leichen oder selbst eigene Außtretung derer Einwohnere leer ${ }^{\mathrm{dk}}$ worden seÿn, so pflegt man solches zwar gemeiniglich biß an den Winter Verschloßen zu halten; allein Wir erachteten, unmaßgeblich [k. 146] nützlicher zu seÿn, daß man durch absonderlich hiezu bestellte Persohnen, etwan durch die Pest Einleger solches

\footnotetext{
di Wyraz podkreślony.

dj Wyraz podkreślony.

dk Wyraz podkreślony.
} 
Hauß gleich ${ }^{\mathrm{dl}}$ an Thüren und Fenstern öffne, außwittere, mit dienenden Sachen, oft und starck räuchere, nach diesem mit denen darinnen befindlichen Sachen auf gleiche Art verfahren, wasche, und in Summa, daß alles mit guter Vorsicht vornehme, was zu Sauberung und Reinigung des Hauses und Sachen dienen kan. Geringe Sachen aber können an einen entlegenen Orte zusammengetragen und verbrandt werden, oder auch in die Weichsel geworfen, hier durch wird man Verhütten, daß die Seuche zu mehrer Gefahr derer künftig solches Hauß ofnenden nicht in dem selben Veralten, die jetzige Reinigung auch, weil alles neu und frisch desto sicherer und gewißer Verrichtet werden könne. $\mathrm{Zu}$ dieser zeitigen Reinigung könten auch vornemlich angehalten werden die jenigen, so auß solchem Hause übrig geblieben sind, daß sie es neml. vor sich thun laßen mögen, mit angehängter Bedrohung einer Bestrafung, dafern sie darinen säumig sich finden laßen solten.

\section{[k. 147] Verstorbene. ${ }^{\mathrm{dm}}$}

Trifft sichs nun, wie es sich leider mehr, alß zu offt trift, daß Jemand in diesen Zeiten mit Tode abgienge, so vermeinen Wir unmaßgeblich, daß nöthig seÿn würde, durch die hiezu bestellte Hhn. Medicos und Chirurgos in inqviniren zu laßen, ${ }^{\mathrm{dn}}$-ob solcher-dn würcklich an der Pest gestorben; denn weil ein Unterscheid ist in, oder an der Pest zusterben, so wird auch mit Beerdigung do daßelben ein Unterscheid gehalten werden müßen, so daß, welcher sonsten gewiß an einer anderen weitigen $1^{\mathrm{dp}}$ ordentlichen Kranckheit verschieden, auch mit einem ordentlichem Leichbegängniß, und am behörigen Ort, falß es die hinterbleiben von langen solten, und so weit es gegenwärtige Läufte zulaßen werden, zur Erden bestellet werden

\footnotetext{
dl Wyraz podkreślony.

$\mathrm{dm}$ Wyraz podkreślony.

dn--dn Wyrazy podkreślone.

do Wyraz podkreślony.

dp Cyfra nadpisana.
} 
könne. Sollte aber die $2^{\mathrm{dr}}$ Inficirung an dem selben gewiß befunden worden seÿn, welches auch ohne Inqvinirung alß dem gewiß zu schließen, wenn er in dergleichen Kranckheit gefunden und bedienet worden:

[k. 148] So wird mit Beerdigung deßen Cörpers allerdings eine Restriction gemachet werden müßen. Und ist zwar bereits hierüber E.E.Hw. Raths Verordnung von 7. Sept. 1708. ergangen ${ }^{12}$, darauf Wir und auch beziehen. Was aber noch etwas weiters dabeÿ zuerinnern seÿn möchte, so ist unvorgreiflich dieses:

1. damit Niemand, so in dieser Zeit verstirbet, unter einer gewießen gesetzten Zeit, derer Determinierung ex Judicio derer Hhn. Physicorum zu hohlen seÿn möchte, eingeleget, weniger außgetragen und beerdiget werden möchte, in deme es geschiehet, und unter vielen andern auch hiesiges Ortes Exempel vor zweÿ Jahren an einem Barbier Gesellen es belehret, daß Leuthe vor todt liegen und davor gehalten werden, die an sich doch ${ }^{\mathrm{ds}-n o c h}$ nicht ${ }^{-\mathrm{ds}}$ todt sind. Unterdeßen wird auch nicht sicher und dienlich seÿn, wenn sie auch gar zu lange unaußgetragen bleiben solten. Unsers Erachtens würde eine Zeit [k. 149] von 24. Stunden zulänglich zu dem erstern und wegen des letztern auch so gar nicht unsicher seÿn, doch derer Hhn. Physicorum Judicio hiedurch nichts benommen.

2. damit die Leichen durch die hiezu bestellte untengenandte Pest=Bediente, ihrer Pflicht gemäß, mit geziemendem Gebühr, alß Christen und Menschen anstehet, tractiret, eingeleget, außgetragen und endlich begraben, werden möchten. Und zwar so wird

3. Nöthig seÿn, umb alle Gelegenheit einigen Grauens zubenehmen, damit solche Leiche außerhalb ${ }^{\mathrm{dt}}$ der Stadt begraben werden mögen, entweder an einem $1^{\mathrm{du}}$ absonderlich hiezu anzuweisendem Orthe, welcher bezäumet werden müße, oder, dafern solches nicht füglich zu Wercke gerichtet werden könte, an einen besondern

\footnotetext{
dr Cyfra nadpisana.

ds--ds Wyrazy podkré́lone.

dt Wyraz podkreślony.

du Cyfra nadpisana.

12 Zob.: APT, AmT, kat. II, I-3798, k. 252 i nast.
} 
und den gehenden $2^{\mathrm{dw}}$ entlegenem Orthe des St. Georgen und St. Catharinen Kirch=Hofes, doch was wiedriger Religion und gemeiner Art sind werden müßen vor solche Leichen, erst gemelte [k. 150] Leichen ${ }^{\mathrm{dx}}$ Örther außgesuchet, vor die jenigen aber, so Conditionis Honorationis wären, der St. Lorentz Kirch=Hof destiniret werden, obwohlen auch vor solche der erstere Ort sicher wäre, weil der letztgedachte KirchHof der Stadt und denen gehenden zu nahe ist, wobeÿ aber

4. auch der Befehl an die ${ }^{\text {dy-Todten Gräbere }}{ }^{-d y}$ sehr nöthig seÿn wird, hiemit sie die Leichen tief ${ }^{\mathrm{d} z}$ genug, etwan 3. Ellen, ein sencken mögen.

5. Nachdeme auch gegenwärtige Zeiten allen Pracht und Ubermuth von selbsten Verbiethen, und man auch klahr genug absiehet, wie das bißherig gewohnte Leich=Gepränge nicht so wohl denen Verstorbenen zu Ehren, alß vielmehr eigenen Pracht sehen zulaßen von vielen vorgenommen werden; eine einfältige Leichen=Bestattung auch Gott dem Herren angenehmer seÿn muß, und solche eingeführte Solennitäten nur ohne deme ad Extema und Adiaphora gehören, die ohne Nachtheil unterlaßen werden können: zu geschweigen, daß auch beÿ guten und gesunden Zeiten Erbahre fromme [k. 152] Gemüther in ihren Testamenten alle dergleichen Solennitäten ihrer Beerdigung halber untersagen: So wäre wohl zu wünschen, wann solches alles ea-in der Stille ${ }^{\text {ea }}$ und Einfalt Verrichtet werden könte. Da aber solches nicht zuerhalten stunde, würde es doch zu moderiren seÿn, irgend, daß aller beÿ solchen betrübten Zeiten unanständiger $1^{\mathrm{eb}}$ Pracht einigestellet werde, die Begängnuß $2^{\text {ec }}$ nicht auß dem Sterbhause, alß welches ohne dem gezeichnet werden würde geschehen, $3^{\text {ed }}$ Niemand auß solchem

\footnotetext{
dw Cyfra nadpisana.

$\mathrm{dx}$ Wyraz skreślony.

dy--dy Wyrazy podkreślone.

dz Wyraz podkreślony.

ea- -ea Wyrazy podkreślone.

eb Cyfra nadpisana.

ec Cyfra nadpisana.
} 
Hause, oder der mit den Verstorbenen einige Gemeinschaft in seiner Kranckheit gehabt zu haben befunden oder nur geglaubet würde, mitfolgen, auch die $4^{\text {ee }}$ Schule, wofern sie ja Vorangehen sollte |: wie wohlen es billicher wegen zarter Jügend, die zu Auffasung derer Kranckheiten viel disponirte, alß alte sind, einzustellen wäre :| nicht in großer Anzahl sich einfinden, und auch weit von einander sich paaren mögen.

ef-Versorgung und Wartung der Krancken. ${ }^{-e f}$

Darüber hat E.E: Hw. Rath bereits in $A^{\circ}$ 1708. d. 5. Sept. 24 et 26. Octobr. ${ }^{13}$ besonderen [k. 152] Verordnungen gemachet, dahin Wir Uns beziehen. Nemlich, daß denen selben zu ihrer Versorgung ein gewißer Bürger vorgesetzet werde, deßen Pflicht seÿn kan, eine genaue Lista ${ }^{\mathrm{eg}}$ aller ${ }^{\text {eh}}{ }^{\mathrm{zu}}$ Versorgenden $^{\text {-eh }}$ Krancken zuhaben, darunter Er die im Krancken=Hause befindliche selbst aufzeichnen, derer andern Specification aber, so hin und wieder in= und außer der Stadt sich befinden solten, entweder von den bestallten Pest=Aufsehern, oder von der Praesidence täglich zuempfangen haben wird. Ferner: Alles was ${ }^{\text {ei }}$ Ihme zu Versorgung solcher Krancken, es seÿe ex publico, oder von Privat=Leuthen und denen Freÿgebigkeit wird ${ }^{\text {jj }}$ geliefert werden, wird ${ }^{\mathrm{ek}}$ empfangen, fleißig aufheben, vortheilen und darüber Rechnung ${ }^{\text {el }}$ halten; auch solche Rechnung der Praesidence wochentlich Sonnabends einliefern. Nicht minder, gute Acht haben, damit die Krancken so wohl durch die bestellte Wärtere, alß Zuträgere wohl ${ }^{\mathrm{em}}$ gehalten, gepfleget und versorget werden, in sonderheit, damit des jenige, was er

ed Cyfra nadpisana.

ee Cyfra nadpisana.

ef-ef Wyrazy podkreślone.

eg Wyraz podkreślony.

eh-eh Wyrazy podkreślone.

ei Wyraz przeprawiony.

ej Wyraz nadpisany.

ek Wyraz skreślony.

el Wyraz podkreślony.

em Wyraz podkreślony.

${ }^{13}$ Tekst żadnego z postanowień nie dochował się do naszych czasów. 
denen Zuträgern vor die angewiesene Krancke täglich reichen wird, ihnen auch würcklich ${ }^{\text {en }}$ ohne [k. 153] Kürtzung zukommen möge.

Und damit dergleichen Krancke zu länglichen ${ }^{\mathrm{eo}}$ Vorrath haben könten, so wäre nicht ohne Nutzen, wenn von $^{\text {ep }}$ den Cantzley |: welches auch in denen Römisch-Catholischen Kirche geschehen könnte :| guthertzigen Gemüthern solche Armuth fleißigst recommendiret werde, mit Anweisung, wohin ein Jeder seine frë̈gebigkeit senden könne, nemlich an oben gedachten Krancken Vorsteher. Und zu diesem Behufs könten absonderlich die hiesigen $1^{\text {er }}$ MaltzenBräuere, $2^{\text {es }}$ Fleischere und $3^{\text {et }}$ Beckere angesprochen werden, damit ein Jeder auß Ihnen von deme, was seiner Handthierung ist, und ihnen auß Gottes=Seegen zufließet solcher Krancken Armuth zu hülfe, auch etwas auß Ihrer Freÿgebigkeit zu kommen laßen wollten: Ein MältzenBrauer, wenn er brauet, etwan eine gantze, halbe oder Viertel=Tonne Bier: Ein Fleischer, wenn er schlachtet, und ein Becker, wenn er becket, alles nach eigenem Gefallen, so viel, alß eines jeden Vermögen, außträget, mit gleichmäßiger obigerwehnter Anweisung, wohin es gesendet werden kan. Wobeÿ aber letztern der Vorschlag gegeben werden könnte, damit sie der Armuth zu Liebe beÿ diesen [k. 154] Zeiten unter sich etwas gewißes festsetzen möchten, wie viel ein Jeder nach Proportion seines Backens, dem KranckenVorsteher liefern sollte von jedem Backen, dagegen Ihnen E.E.WettGericht nach Proportion ihrer bewilligkeit Lieferung die Taxa des Brodts erhöhen könte, wodurch also die Armuth mit Brodt von allen Consumenten der Stadt versorget würde.

Gleicher Gestalt könten auch die Leguminen ${ }^{\mathrm{eu}}$ von denen Kornhändlern erbethen werden, weil aber derer importance geringe, so wird es der ordentl. Pest=Cassa keinen großen Abbruch thun, und ist auch zuglauben, daß auch darinnen durch eines und des andern freÿgebigkeit kein Mangel seÿn wird.

\footnotetext{
en Wyraz podkreślony.

eo Wyraz podkreślony.

ep Wyraz podkreślony.

er Cyfra nadpisana.

es Cyfra nadpisana.

et Cyfra nadpisana.

eu Wyrazpodkreślony.
} 
ew-Pest=Bediente-ew

Wegen solcher hat zwar E.E.Hw. Rath bereits in $\mathrm{A}^{\circ}$. 1708. diebq. 12. 17. 19. 21. Sept. 1. 2. 15. 16. 24 et 26. Octobr. ${ }^{14}$ gewiße Verordnungen gemacht, dahin Wir uns auch referiren. Nemlich es sind bestellet gewesen

1. ex-Pest-Aufwärtere ${ }^{-e x}$, und Pest=Aufwärterinnen, derer Pflicht seyn $1^{\text {ey }}$ die Krancken Persohnen, vermöge Anweisung des Krancken Vorstehers fleißig zu warten und zupflegen, [k. 155] $2^{\mathrm{ez}}$ was sie zu ihrer Versorgung von den Pest=Zuträgern tägl. empfangen wird, es seÿe ex publico oder auf Anordnung der Vermögenden Krancken selbst, es richtig denenselben reichen, $3^{\text {fa }}$ wenn sie sterben sollten, es sofort dem herumb gehenden Pest=Aufseher melden, $4^{\mathrm{fb}}$ sich unter die andern Gesunden Leuthe nicht mengen, $5^{\text {fc }}$ nicht untren an der Persohn durch vorsetzliche Beförderung seines Todes, noch an den Sachen des Krancken werden pp.

2. ${ }^{\mathrm{fd}}-$ Pest=Einlegere ${ }^{-\mathrm{fd}}$, fe-Pest=Trägere ${ }^{-\mathrm{fe}}$ und ${ }^{\mathrm{ff}}$-Todten=Gräbere ${ }^{-\mathrm{ff}}$. Von denen zweÿtern sind Acht von E.E.Hochw. Rath auf Recommendation der SterbeZunft außer denen in den Vorstädten angenommen worden, nebenst einem Vorgänger, denen von den Erstern zweÿ Kerlen zu Abwaschung und Einlegung der Todten zugegeben sind, und der Ersten waren auch Achte. Die Pflicht derer $1^{\mathrm{fg}}$ zweÿtern, neml. der Trägere ${ }^{\mathrm{fh}}$ seÿn, daß sie $1^{\mathrm{fi}}$ von denen, so in der Sterbe=Zunft sind, weil Sie von ihnen besoldet werden,

ew-ew Wyrazy podkreślone.

ex-ex Wyrazy podkreślone.

ey Cyfra nadpisana.

ez Cyfra nadpisana.

fa Cyfra nadpisana.

fb Cyfra nadpisana.

fc Cyfra nadpisana.

fd--fd Wyrazy podkreślone.

fe Wyraz podkreślony.

ff Wyraz podkréślony.

fg Cyfra dopisana na marginesie.

th Wyraz podkreślony.

fi Cyfra dopisana.

${ }^{14}$ Tekst żadnego z przytaczanych postanowień nie dochował się do naszych czasów. 
nichts nehmen, von denen andern aber, so außer derselben [k. 156] stehen, nicht höher alß fl. 6. biß 12. fordern, von den armen aber, was ihnen gerichtet würde, zufrieden seÿn, auch nach Bewandnüß nichts nehmen, $2^{\text {f }}$ sub täglich Gott ergeben, $3^{\text {fk }}$ nüchtern und mäßig leben, $4^{\mathrm{A}}$ unter die andere Bürgerschaft nicht außgehen, $5^{\mathrm{fm}}$ und ihnen den Lebens=Unterhalt durch die Ihrigen zutragen laßen. $2^{\text {fn }}$ fo-Die Pest-Einlegere ${ }^{- \text {fo }}$ Pflicht außer denen Generalib. seyn: daß sie $1^{\text {fp }}$ auf erhalten Befehl von dem Leichen=Aufseher sich so fort $\mathrm{zu}$ den angewiesenen todten verfügen, $2^{\mathrm{fr}}$ den selben abwaschen, $3^{\text {fs }}$ und wenn es rechte Zeit ist, so ihnen von ebenden selben soll gemeldet werden, einlegen und den Pest=Trägern ferner überliefern, übrigens $4^{\mathrm{ft}}$ den Cörper bescheidentlich und gebührlich, alß einen MitMenschen und Christen handhaben $5^{\mathrm{fu}}$ nichts in dem Hause rühren, weniger entwenden pp.

3. fw $^{\text {Der }}{ }^{\text {fy-Todten}=G r a ̈ b e r e ~}{ }^{-f y}$ Pflicht seÿe, außer denen Generalibq.: $1^{\mathrm{fz}} \mathrm{da}$ sie die Cörper, so wie sie von den Trägern empfangen, in die Erde sencken, $2^{\text {ga }}$ nichts an ihnen rühren, $3^{\text {gb }}$ den Särg nicht öffnen, $4^{\mathrm{gc}}$ die Grube biß 3. Ell. tief graben und wohl verschütten pp. [k. 157] Weil auch wegen der Todten=Wagen und Pferde ein Verordnung von E.E. Hw. Rath sub Acta 1708. d. 21 Sept. ist, auch solche

fi Cyfra dopisana.

fk Cyfra dopisana.

fl Cyfra dopisana.

fn Cyfra dopisana na marginesie.

fo-- fo Wyrazy podkreślone.

fp Cyfra nadpisana.

fr Cyfra nadpisana.

fs Cyfra nadpisana.

ft Cyfra nadpisana.

fu Cyfra nadpisana.

fw Cyfra dopisana na marginesie.

fy- fy Wyrazy podkreślone.

fz Cyfra nadpisana.

ga Cyfra nadpisana.

gb Cyfra nadpisana.

gc Cyfra nadpisana. 
Wagen zweifels ohne noch vorhanden seÿn werden, so laßen Wir es dabë̈ beruchen.

Außer obigen erachteten Wir unmaßgeblich nöthig zu seÿn, damit die oben oft allegirte:

1. Pest, oder Leichen=Aufseher ${ }^{\text {gd }}$, und zwar zu Einem in jedem Qvartiere und in der Mocker Zweene bestellet würden. Ihr Nützen erhellet auß ihrer Pflicht ${ }^{\text {ge }}$, welche diese seÿe: daß sie außer den Generalibq., ein Jeder $1^{\text {gf }}$ in seinem Qvartier und Orthe täglich zweÿ mahl Vor= und NachMittag die Hauser begehe und nachfrage thue, wo sich Krancke und Verstorbene eußern möchten, davon Er täglich der Praesidence und auch zugleich dem Krancken=Vorsteher eine Lista einhändige: ferner, die Verordnung mache, $2^{\mathrm{gg}}$ damit die Leichen in gesetzte Zeit durch die Einleger gewaschen und eingeleget, durch die Trägere außgetragen und die Todten Gräbere begraben [k. 158] werden, sich in deßen an obspecificirte Persohnen nicht zu nahe mache; $3^{\text {gh }}$ was auf den Gaßen und Straßen von Krancken oder Todten gefunden werden sollte, aufzeichnen, damit die letztern durch die in der Vorstadt bestellte Trägere weggeschaffet und folglich in gehöriger Zeit begraben, die ersten aber an die Örther, welche die Praesidence anweisen wird, ohne Säumniß gebracht werden, fleißig anordnen, und nechst dem $4^{\text {gi }}$ genaue Nachforschung thue, auß welchem Hauße der Krancke oder Todte seÿe. 5 ${ }^{\text {gi }}$ Wo was auf den Gaßen und Straßen an Lumpen oder andern dergleichen Sachen gefunden würde, alles durch die Pest=Einleger aufnehmen, und vor der Stadt an einem entlegenen Orthe verbrennen laße. $6^{\mathrm{gk}}$ Das Bettel

gd Wyraz podkreślony.

ge Wyraz podkreślony.

${ }^{g}$ Cyfra nadpisana.

go Cyfra nadpisana.

${ }^{\text {gh }}$ Cyfra nadpisana.

gi Cyfra nadpisana.

gi Cyfra nadpisana.

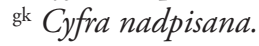


Gesinde beÿ der Praesidence angebe, $7^{\mathrm{gl}}$ genau nachforsche, ob nicht jemand, deme außzugehen Verbothen, ohne an sich habendes obenbeschriebenes Zeichen, oder, welche Verdächtig, ja gar die inficirende Kranckheit am Leibe mit sich herumbführten, sich auf den Gaßen [k. 159] und Straßen sehen laßen, und falß er Jemand davon betrifft, ihn so fort beÿ der Praesidence melde. In Summa Gaßen und Straßen von Krancken, Todten und außgeworfenen Leuthen, auch Bettel=Gesinde rein halten, und ein gut Register ${ }^{\text {gm }}$ von Leichen und Krancken, in den Häusern täglich conficire und der Praesidence liefern pp.

2. Pest $=$ oder Krancken=Zuträgern ${ }^{\text {gn }}$.

Die Anzahl der selben kan man nicht eigentlich benennen, denn nach deme Krancken sich mehren oder mindern, so mehren und mindern sich die Zuträgere nebst der Wärtern. Der Nutzen erhellet auß der eintzigen Pflicht ${ }^{\mathrm{go}}$, welche diese seÿe: $1^{\mathrm{gp}}$ das sie den Krancken das Eßen und Trincken, auch andere Nothdürft zu tragen, vor das Hauß setzen, davon es hernach die Pest=Wärtere nehmen, und dem Krancken bringen. Diese beede letztgedachte, weil sie den Krancken nicht nahe, weder ins Hauß kommen dürfen, sind so gefährlich vor andere nicht, alß die andern Pest=Bedienten, unterdeßen werden sie [k. 160] mehrer Sicherheit halber, doch gleich andern, $2^{\text {gr }}$ eine a parte Wohnung haben und sich aller Gemeinschaft mit andern gesunden, obwohlen nicht so entfernert, alß die andern, enthalten müßen.

3. Pest $=$ Hebamme. ${ }^{\mathrm{gs}}$

Weil diese hochnöthig und eine a parte zubestellen, sich nicht füglich thun läßet, so kan man von denen Pest=Wärterinnen ${ }^{g t}$ Eine, oder Zweÿ, nach Vorgängigen Examine durch die Hhn. Physicos auch dazu bestellen,

\footnotetext{
${ }^{\mathrm{gl}}$ Cyfra nadpisana.

gm Wyraz podkreślony.

gn Wyraz podkreślony.

go Wyraz podkreślony.

sp Cyfra nadpisana.

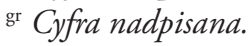

ss Wyraz podkreślony.

gt Wyraz podkreślony.
} 
denen etwas mehrers, alß durch andern Wärterinnen gerichtet werden könte. Solte man aber darunter keine tüchtige finden können, so müße man schon eine besondere ${ }^{\mathrm{gu}}$ hiezu ex publico halten, es seÿe dann, daß sich von den Pest-Chirurgorum, oder derer Pest=Trägere Haußfrauen hiezu solte welche geschickt finden und brauchen laßen wollen.

Sämtlicher obigen Pflicht insgemein ist: $1^{\mathrm{gw}}$ Gott vorauß vor Augen haben, $2^{\mathrm{gy}}$ nüchtern und mäßig leben, $3^{\mathrm{gz}}$ behertzt und [k. 161] Gott gelaßen seÿn, $4^{\text {ha }}$ treu, fleißig und behutsahm in seinen ${ }^{\text {hb }}$ ihren Biedienungen handeln, $5^{\text {ho }}$ nicht unter Gesunde sich mengen, $6^{\text {hd }}$ nicht ausgehen, es seÿe dann mit einem gewießen Zeichen, etwan mit einem Weißen auf die Ober=Kleider geneheten Creutze oder sonsten, doch anders, alß die Verdächtigen, damit man sie unterscheiden könne; $7^{\text {he }}$ bedencken, daß sie nicht umb eigenen Nützens, sondern umb Gottes Willen diese Gottwolgefällige Bedienung führen, $8^{\text {hf }}$ sich mit den Krancken geduldig und sanftmüthig begehen, $9^{\text {hg }}$ von Leuthen nichts über gebühr erpreßen, den Armen aber ohne Entgeldt dienen p.p.

Welcher wieder solche generale v. speciale Pflicht handelt, wird billig mit einer Strafe ${ }^{\text {th }}$, theils am Geld |: so der Pest=Cassa zum besten gehen kan :| theils am Leibe, theils sonsten arbitrarie beleget, deren speciale Determinierung E.E:E. Hw. Rath Wir hiemit überlaßen.

\footnotetext{
gu Wyraz podkreślony.

${ }^{\mathrm{gw}}$ Cyfra nadpisana.

gy Cyfra nadpisana.

${ }^{g z}$ Cyfra nadpisana.

ha Cyfra nadpisana.

hb Wyraz skreślony.

hc Cyfra nadpisana.

hd Cyfra nadpisana.

he Cyfra nadpisana.

hf Cyfra nadpisana.

hg Cyfra nadpisana.

hh Wyraz podkreślony.
} 